\title{
Subungual Osteochondroma: A Diagnosis to be remembered
}

\author{
Gustavo Moreira Amorim ${ }^{1,2}$, Carolina Krause1, Bruna Garcia da Silveira', Bruna Molozzi², Ingrid Reuwsaat \\ Paul $^{2}$, Roberto Moreira Amorim Filho ${ }^{2}$ \\ ${ }^{1}$ Faculty of Medicine,South Santa Catarina University
}

Received: January 30, 2021; Accepted: February 10, 2021; Published: May 04, 2021

*Corresponding author: Gustavo Moreira Amorim, MD, Msc, 1Faculty of Medicine,South Santa Catarina University, Brazil, Tel. No: +5548999827097; E-mail: gustavomoreiraamorim@hotmail.com.

\begin{abstract}
We report a case of a 14-year-old male patient who came to our outpatient clinic to be evaluated from a recently developed painful hallux lesion, determining nail dystrophy. He had previously been treated with trichloroacetic acid for a supposed subungual common wart. After examining a firm and painful nodule, emerging from the nail bed, elevating the nail plate, we recommend an X-ray examination, confirming our suspicion of a subungual osteochondroma. The patient was referred to the orthopedist, a foot specialist, for surgical treatment.
\end{abstract}

Keywords: Nail Diseases;BoneNeoplasms;Exostosis;Osteochondroma; Osteochondroma / Diagnostic Imaging; Subungual

\section{Dear Editor}

We recently came across an interesting and illustrative case that we consider important to report.A 14-year-old male patientcame to our outpatient clinic with a painful lesion on his right big toe (hallux). He noticed the appearance of a small papule at the distal end of the toe about 6 months ago. Initially, he associated with a minor trauma during a soccer match, but the lesion showed a slowly progressive enlargement, with intensification of the pain and alteration of the nail plate.

He was seen at the basic health unit by the family physician. A common wart was diagnosed and a chemical cauterization with $70 \%$ trichloroacetic acid was performed. Since the procedure was unsuccessful, he was referred to a dermatologist.

During the clinical-dermatological examination, we identified a nodule emerging from the nail bed. Its surface showed keratosis surrounding central erosion. The height of the lesion determined the lifting of the nail plate.

History and clinical examination made it possible to formulate the diagnostic hypothesis of subungual osteochondroma, and, as differential diagnosis, exostosis, pyogenic granuloma and common wart.

X-ray examination of the affected foot/toe confirmed the diagnosis of subungual osteochondroma. The patient was referred to a foot specialist orthopedist for surgical treatment.

Although osteochondromas are the most common bone tumors, representing 10 to $15 \%$ of the totality, subungualosteochondromas is quite rare [1-4]. It is a benign osteocartilaginous tumor that usually involves the phalanges of the toes or fingers, affecting most commonly the distal phalanx of hallux [4].

The first description is attributed to Dupuytren, in 1817. The author described as a bony outgrowth of the distal phalanx [3].

Subungual osteochondromas occurs mainly in adolescents and young adults. Although there are some discordant works, most authors found an equivalence between the sexes [2,3]. The most common topography of involvement is the distal phalanx of the hallux, however it can occur on any finger or toe [4-6].

Etiology of the osteochondromas is still unknown [4]. It is considered a developmental lesion rather than a true neoplasm [7]. Some consider it to be a reactive metaplasia resulting from microtrauma, others to be a congenital subclinical lesion that growths and become clinically relevant over the years, but the fact is that there is no conclusive evidence in the literature to support a particular pathogenesis $[1,4,8,9]$.

Clinically, subungual osteochondromas present as firm solitaryerythematous-nodule, usually small, projecting from the free edge of the nail. The overlying nail may become brittle and may be lifted or become detached [1,2]. It may be asymptomatic, but usually patients refer pain and oppression in the affected finger or the toe [10].

Subungual osteochondroma is often misdiagnosed because of its rare incidence and similarity to a number of nail, soft tissue, and bony pathologies [3].

The diagnosis can be confirmed by clinic examination and simple radiography in dorsopalmar and oblique projections. Still, gold standard for the diagnosis remainsthe histopathology exam [2].

Differential diagnosis should be made with exostosis, fibromas, warts, pyogenic granuloma, keratoacanthoma, glomus tumor, myositis ossificans, squamous cell carcinoma and melanoma [13].

Surgical excision is the treatment of choice. Recurrence rates are significant; however they are directly linked to the technique, usually due to incomplete lesion removal. 


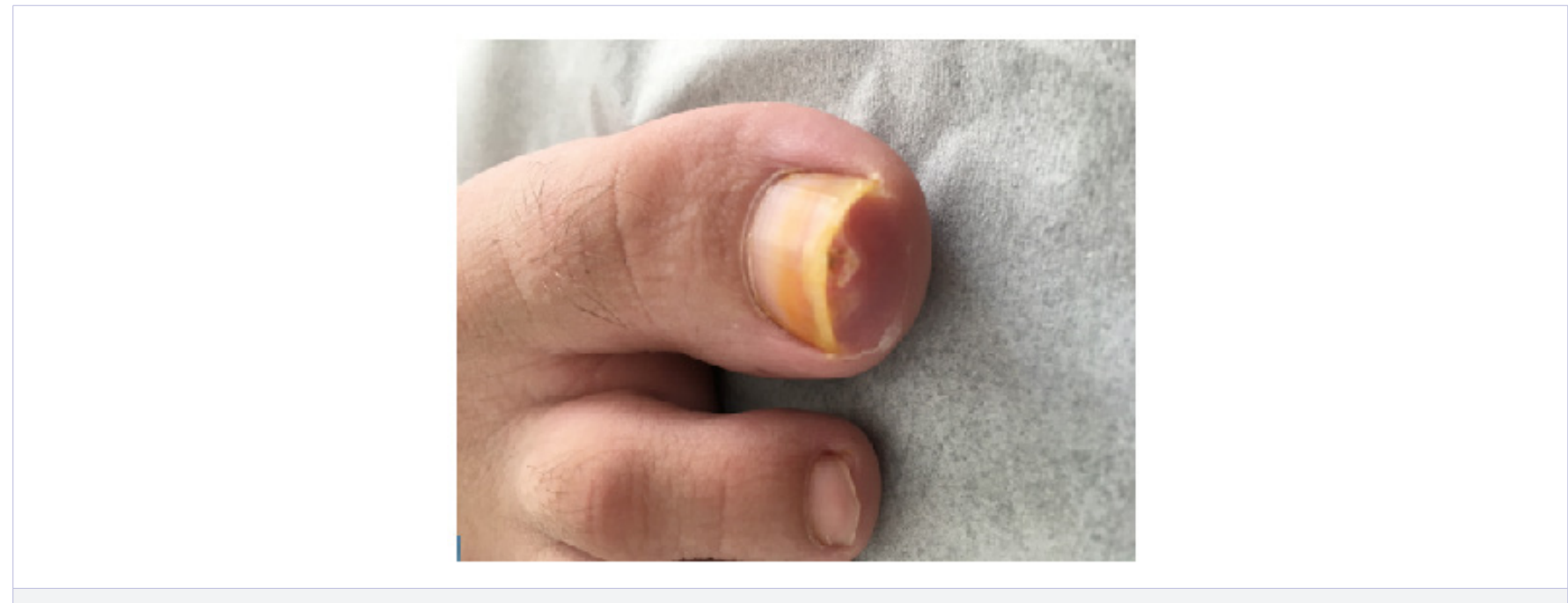

Figure 1: Small nodule arising from the nail bed, causing onycholysis of the nail plate

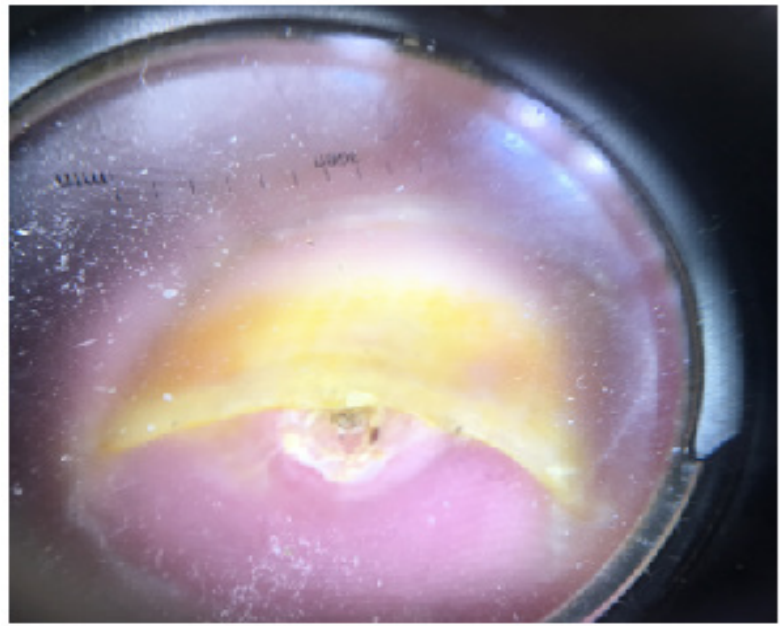

Figure 2: Dermoscopy of the nail free edge showing a hyperkeratosis surrounding a central eroded area, along with onicolisis of the central area of the nail plate.

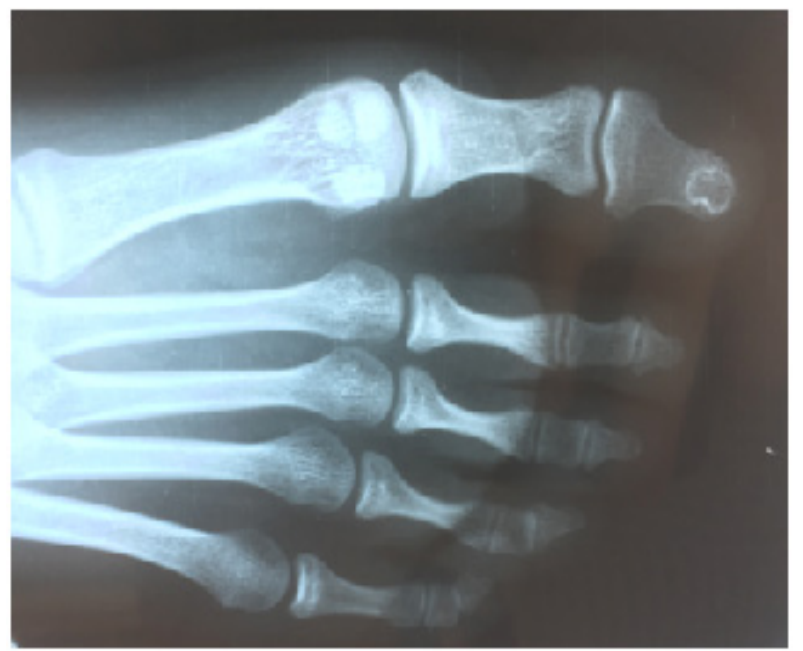

Figure 3: X-Ray examination showed a sessile image by expansion of the trabecular bone from the epiphyseal region of the distal phalanx of the right hallux. . 
With this case, we want to draw attention of the dermatologist and even the general practitioner to the subungual osteochondroma that, although uncommon, can be seen in clinical practice. We would like to emphasize the importance of a careful history, meticulous examination, adequate confirmation through imaging and treatment in a multidisciplinary approach.

\section{References}

1. Flores H, Cherit J, Memije ME, De-Ocariz M. Subungueal Osteochondroma: Clinical and Radiologic Features and Treatment. Dermatol Surg. 2004;30(7):1031-1034.

2. Franklin TP, Miguel MQ Félix MR, Leydi MQ Herbert PC. Subungual Osteochondroma: Review of the Literature. MOJ Orthop Rheumatol. 2017;8(5):00327.

3. Tiwari A, Agrawal N, Verma T, Hitesh L. Subungual Osteochondroma: Nail Sparing Excision. J Clin Orthop Trauma. 2016;7(Suppl 1):72-75.

4. Mavrogenis A, Papagelopoulos P, Soucacos P. Skeletal osteochondromas revisited. Orthopedics. 2008;31(10):1018-1028.

5. Dumontier CA, Abimelec P. Nail unit enchondromas and osteochondromas: a surgical approach. Dermatol Surg. 2001;27(3):274-279.

6. Kim SW, Moon SE, Kim JA. A case of subungual osteochondroma. J Dermatol. 1998;25(1):60-62.

7. Murphey MD, Choi JJ, Kransdorf MF, Flemming DJ, Gannon FH. Imaging of osteochondroma: variants and complications with radiologicpathologic correlation. Radiographics. 2000;20(5):1407-1434.
8. Toyoda M, Morohashi M. An ultrastructural study of subungual exostosis, with special reference to intranuclear inclusions. Med Electron Microsc. 1998;31:142-146.

9. Eliezri YD, Taylor SC. Subungual osteochondroma: diagnosis and management. J Dermatol Surg Oncol 1992;18(8):753-758.

10. Schulze KE, Hebert AA. Diagnostic features, differential diagnosis, and treatment of subungual osteochondroma. Pediatr Dermatol. 1994;511(1):3941. 